\title{
Moulding student emotions through computational psychology: affective learning technologies and algorithmic governance
}

\author{
Ben Williamson, Faculty of Social Sciences, University of Stirling \\ Post-print version of article published in Education Media International: \\ https://doi.org/10.1080/09523987.2017.1407080]
}

\begin{abstract}
Recently psychology has begun to amalgamate with computer science approaches to big data analysis as a new field of 'computational psychology' or 'psycho-informatics,' as well as with new 'psycho-policy' approaches associated with behaviour change science, in ways that propose new ways of measuring, administering and managing individuals and populations. In particular, 'social-emotional learning' has become a new focus within education. Supporters of social-emotional learning foresee technical systems being employed to quantify and govern learners' affective lives, and to modify their behaviours in the direction of 'positive' feelings. In this article I identify the core aspirations of computational psychology in education, along with the technical systems it proposes to enact its vision, and argue that a new form of 'psycho-informatic power' is emerging as a source of authority and control over education.
\end{abstract}

Keywords affective computing, big data, biometrics, computational psychology, psycho-informatics, socialemotional learning

Digital technologies are never simply neutral tools or devices but the products of complex interplays of technological innovations with social arrangements. As the field of science and technology studies (STS) has demonstrated, technologies are produced, deployed, configured and used in specific social and political contexts (Gillespie, Boczkowski \& Hood 2014). As such, STS has shown how 'technological objects' are 'thoroughly enmeshed in society, as integral components of social order,' which have been fashioned to encourage, exclude or regulate certain behaviours (Jasanoff, 2015, pp. 2-3). Informed by the STS outlook, recently studies have begun to focus on digital technologies, software, code and algorithms, and traced how they are both socially produced and socially productive of particular effects - such as new ways of doing things, new forms of social and economic relations, new modes of cultural activity, and new ways of exchanging information and producing knowledge (Kitchin \& Dodge 2011). Studies of software have also been undertaken in the field of education research, focusing on how educational technologies are produced in relation to particular policies, commercial aspirations and scientific insights, and which produce effects as they are then inserted into other policymaking processes, management techniques, knowledge exchange, and pedagogic practices (Lynch 2015; Williamson 2017).

This article focuses on the emergence of 'computational psychology' in education, and specifically examines new digital technologies designed to capture psychological data about learners. Although computational psychology as a branch 
of psychological research has a relatively long history of cognitive modelling, it has recently begun to make extensive use of sources of 'big data' to enable scientists to understand, predict, and intervene in human behaviours; this shift to big data analytics in psychological research has been termed 'psycho-informatics' (Markowetz et al 2014). However, the application of powerful computational methods to big data in order to generate psychological insights has become controversial at the present time as it has been revealed how social media data have been used for purposes of emotional manipulation and the production of psychological profiles for voter micro-targeting in political elections (Woolley \& Howard 2017). Even some Silicon Valley engineers have begun to worry about the negative psychological and neurological consequences of social media's 'psychological tricks' on people's attention and cognition, and their potential implications for democracy as people's political attention is shaped by trending topics and social media filters (Lewis 2017). Computational psychology and associated psycho-informatic techniques have therefore become powerful sources of social control and management, used in both political and commercial attempts to govern and regulate certain behaviours, emotions and actions (Ruppert, Isin \& Bigo 2017).

Within education, new technologies are being designed and deployed to scrape emotional data from students and then sculpt their emotions and subjectivities (Nemorin 2017). In the following sections I identify the core aspirations of computational psychology and its application in current educational thinking, and detail the technical systems it proposes to enact its vision, in order to argue that a new form of 'psycho-informatic power' is emerging as a source of authority and control over education. Psycho-informatic power emphasizes how combined political and commercial interests and financial investment are flowing toward companies, researchers and products that promise to be able mine the emotions using a combination of digital data-processing software and psychological methods for both political and business ends and purposes. The chapter examines mobile apps and platforms that enable teachers to collect and track emotional data from students based on behavioural observations in the classroom, 'affective computing' technologies that can read emotions through facial vision algorithms, and wearable 'biometric' devices that capture emotional data from the skin.

An ontological challenge is raised by psycho-informatic power. Lynch and Gerber (2017, p. 4) have queried ontological assumptions about 'what digital is,' highlighting that the digital is actually a 'complex assemblage of human and computational languages' which determine how things are subjected to 'simplification and standardization' for computation. All software, they argue, has to be 'authored' to achieve certain aims, and from there acts as an 'authoring tool' to 'enable and inhibit what can be known' and done (Lynch \& Gerber, 2017, p. 4). 
With psycho-informatics come ontological assumptions that affective data can be scraped from the body via behaviour tracking, affective computing and biometric applications, and then sculpted through particular technical interventions. As with all software, however, psycho-informatic technologies have to be authored for particular purposes, with implications for what and how the psychological correlates of emotions and behaviours are known and may be materially acted upon. Insofar as psycho-informatics is intended to intervene in behaviours and shape emotions, its software applications also need to be understood as authoring tools for scripting politically and commercially desired feelings on to the minds and bodies of users. This article traces how an ontology of psycho-informatic power which assumes the human emotions can be read from digital data is leading to attempts to write and imprint preferred forms of conduct on to bodies and minds through computational psychology in education.

\section{Computational psychology}

The involvement of computer technologies in psychological forms of political and social ordering already has real-world applications. Much concern has been raised recently about the alleged involvement of the 'psychographic' data company Cambridge Analytica in the use of psychological personality information to 'microtarget' potential voters with 'computational propaganda' during the 2016 Brexit referendum and US presidential campaign (Grasseger \& Krogerus 2017). Some have called it 'weaponized AI propaganda' and 'automated behaviour change' (Anderson \& Horvath 2017): a combination of 'big data surveillance' and 'computational psychology' that uses personal data harvested from the web to construct detailed psychological profiles and predict potential voting habits, then ultimately change behaviours by emotional manipulation of people's feelings via 'micro-propaganda' (Albright 2016).

The marketing claims of data analytics companies like Cambridge Analytica to be able to know and target people through psychographics may ultimately be questionable, relying on overstretched claims to data analytic precision and accuracy. Its animating vision of being able to enact social control through both real-time knowledge and psychological and behavioural change, however, has political force (Beer 2017). Indeed, Cadwalladr (2017) has detailed how Cambridge Analytica and its network of commercial, financial, political and military supporters and partners have embarked on an experimental program of 'psychological warfare' through computational propaganda, claiming that it 'is not just a story about social psychology and data analytics. It has to be understood in terms of a military contractor using military strategies on a civilian population.' A major research project on 'computational propaganda' and 'political bots' worldwide has 
provided evidence of how 'computational propaganda is produced, managed, and circulated' and how 'social media are actively used as a tool for public opinion manipulation' in a variety of national contexts (Woolley \& Howard, 2017, pp. 2-3).

The use of computational psychology for civic and political purposes is a manifestation of other, more mundane attempts to conduct forms of 'psychological surveillance' and 'psychological governance' through digital technologies_or what is termed 'psycho-informatic power' in this article. Digital media organizations are starting to perform important civic roles, and acquiring 'civic power' as a result:

The services these intermediaries offer can influence, shape and help determine people's wants, since these organisations now play a significant and growing role in the extent to which citizens acquire information, communicate with one another, relate to authorities, and represent themselves. (Moore, 2016, p. 23)

The civic power of digital intermediaries such as Facebook, Google, Amazon and so on has its basis in their monopolistic commercial command of public discourse and attention, and gives these organizations unprecedented capacity to shape people's attention, choices, and sentiments. In this context, psychological profiling through user data is seen as an increasingly appealing strategy both for businesses and governments. Davies (2017) has argued that businesses and governments alike are increasingly interested in making people's emotions visible using advanced sensing technologies such as facial recognition systems, wearable mood monitoring devices, and even brain-scanning technologies. These devices might then be able to provide feedback on the user's feelings, prompting a change in behaviour in the direction of more preferable positive emotion-particularly those that have certain quantifiable value in the economy. Such techniques are consistent with the behaviour change agenda associated with the psychological field of behavioural economics, which has in recent years concentrated political attention on human emotions, and sought to develop policy techniques to 'nudge' the 'suboptimal citizen' to make decisions that maximize their own emotional health and societal well-being at the same time (Jones, Pykett \& Whitehead 2013).

Of course, psychology has long played a role in government thinking. Rose (1999) has shown how the expertise of the 'psy-sciences' has been influential in the management of workplaces, the military, the family and homes, schools, and even selfhood. The psy-sciences have made it possible to understand human qualities such as behaviour, mental health, development and intelligence, in ways that have allowed practical techniques to be developed to act upon human capacities for specific objectives. Psy, in other words, has made the human calculable and manageable, and turned spaces such as offices and classrooms into 'mini- 
laboratories' for measuring human qualities and then acting upon them to improve them (Rose 1999).

Through the behaviour change agenda and techniques of psychological governance, the psy-sciences are playing an increasingly influential part in governmental policymaking. Friedli and Stearn (2015) have described 'psychopolicies' which rely on the surveillance of citizens' psychological characteristics, and 'psycho-compulsion' techniques that then impose psychological explanations on behaviours plus interventions that are designed to modify attitudes, beliefs and personality in the direction of positive affect. In relation to children's services such as education, McGimpsey, Bradbury and Santori (2016) have likewise noted how sources of psychological policy knowledge treat the individual as a site of intervention, articulated in terms of the measurement of emotional states and capacities along with projected future outcomes, who can then be subjected to behaviour change policies designed to promote 'desirable' behaviours and politically preferred feelings. Moulding student emotions is thus a 'smart investment' for the future (McGimpsey et al, 2016).

With the emergence of big data the psy-sciences stand poised to make digital data analyses into a key method for understanding and acting upon people's behaviours and feelings. The new field of 'psycho-informatics' is based on the application of computer science techniques to psychological tracking, measurement and analysis of behaviours, emotions, personality traits, attitudes, cognition and abilities. It employs a combination of behavioural data sources such as wearable sensors to track movements; smartphones to trace online activities; central 'big data' stores of unprecedented quantity for psychological analysis; and analytical platforms that use techniques from data mining and machine learning to detect, characterize and classify behavioural patterns and trends of the 'transparent human' (Markowetz et al, 2014).

The use of psychological data about people to predict, target and change their emotions and behaviours has been described as 'hypernudging,' which makes use of both 'persuasive computing' techniques of 'hooking' users and of behavioural change science insights into how to 'trigger' particular actions and responses (Yeung, 2017). The consequences of the governmentalization of big data and persuasive computing for civic and commercial purposes have been conceptualized as 'algorithmic governance'- the automated collection, aggregation and analysis of big data, using algorithms to model, anticipate and pre-emptively affect and govern possible behaviours (Rouvroy \& Berns, 2013). It involves constant digital surveillance of behaviours, the automated production of knowledge through data mining and analysis of those behaviours, and then action on those behaviours using predictive knowledge to anticipate and pre-empt possible future activities. 
Understood in this way, algorithmic governance is based on an updated Foucauldian conceptualisation of biopolitical governing, which relies on statistical knowledge of individual lives and total populations to govern how individual people and collectives alike lead their lives (Foucault, 2008). Biopolitics signifies particular strategies of power that are rooted in distinct disciplinary practices, authoritative forms of knowledge, and the historical truths they propose, which might then be translated into specific practices for intervening in and governing human lives (Rabinow \& Rose, 2006), such as 'practices of correction, exclusion, normalization, disciplining, therapeutics and optimization' (Lemke, 2011, p. 5). Bringing a biopolitical perspective into the domain of social media, CheneyLippold (2011) describes a big data-driven algorithmic 'soft biopolitics' that uses people's digital data traces to construct digital profiles of their everyday lives, which may then be used in future attempts to intervene in what people do. Big psychological data and practices of algorithmic governance combined with the power of digital media companies, then, constitute an emerging form of biopolitics which is targeted at pre-empting actions and behaviours_or psycho-informatic power.

Psychological forms of big data analysis such as psycho-informatics and computational psychology are now being considered as a viable approach to the understanding of education and learning. As a field of research, education has been dominated by psychology for a century. Early pioneers of psychology in education such as EL Thorndike long ago sought to identify the 'laws of learning' through statistical analysis, which might then inform the design of interventions to improve 'human resources' and thereby contribute to the optimization of 'industrial management' techniques both within the school and the workplace (Peters \& Tesar, 2017). Today, however, the Thordikean concern with the industrial management of human resources through the institution of the school is mutating into the algorithmic governance of behaviours and affects through digital apps and platforms. This pre-emptive biopolitics of education is being made possible by the amalgamation of psychology with computer science-to become computational psychology or psycho-informatics - as well as with new psycho-policy approaches associated with behaviour change science such as 'hypernudging,' in ways that propose new ways of measuring, administering and managing the learner. As an amalgamation of psycho-policy techniques of nudging and triggering with the soft biopolitics of algorithmic governance, psycho-informatic power describes the control and use of computational psychology for the purposes of governing human emotions.

\section{Education, data science \& social-emotional learning}


Big data and the data science methods required to collect, store and analyse it have become a significant interest in education in the last few years (Williamson 2017). In particular, a new field of 'education data science' has emerged to undertake big data analyses in education. Education data science consists of professional expertise such as computer engineering, data science, statistics, cognitive psychology, neuroscience, learning science, psychometrics, and bioinformatics; techniques and methods including data mining, text-mining, machine learning, predictive analytics, network analysis, and natural language processing; applications such as recommendation engines for learning, learning analytics, adaptive learning platforms, wearable biometric sensors, and computer-adaptive testing; and normative and transformative educational aspirations including personalized learning, social networked learning, and optimizing learning. The dominant focus of much education data science in its early years has been on measuring and predicting student progress and attainment, and then on 'optimizing' learning and the environments in which it takes place. Importantly, education data science is not just an academic field of inquiry. Its main applications have been developed in the commercial education technology sector. Education data scientists from both academic and commercial settings have also sought to apply their professional expertise, techniques, methods and applications, and their normative aspirations, to the area of 'social-emotional learning.'

'Social-emotional learning' (SEL) is the term given to a range of 'personal qualities' sometimes described as the 'non-academic' or 'non-cognitive' dimensions of learning (Duckworth \& Yeager, 2015). It includes such concepts as self-control, well-being, perseverance, happiness, resilience, growth mindset, grit, social intelligence, and character, all of which derive from a 'psycho-economic' fusion of positive psychology with behavioural economics or behaviour change science (Bates, 2017). The psy vocabulary of SEL is the product of a transnational network of influencers such as psychological research centres, think tanks, international non-governmental organizations, psychological entrepreneurs, and government agencies, all of which have adopted and helped diffuse their theories of noncognitive learning to build policy consensus and mobilize pedagogic practices that build positive behaviours and affects.

The OECD (best known for its global standard tests), for example, has established a 'Skills for Social Progress' project to focus on 'the power of social and emotional skills' (OECD-CERI, 2015). Its central assumption is that SEL skills can be measured meaningfully and that such measures can be instrumental to help decision makers assess children's current skill sets and future needs in order to improve their life prospects and contribute to societal progress. Another international organization, the World Economic Forum, has projected its own 'New Vision for Education' which involves 'fostering social and emotional learning 
through technology.' Its vision is that SEL proficiency will equip students to succeed in a swiftly evolving digital economy, that digital technologies could be used to build 'character qualities,' and that artificial intelligence and multimodal social computing could help improve cognitive, social and emotional skills (WEF 2016).

New influential organizations have been formed to promote SEL practice and assessment, such as the Collaborative for Academic, Social, and Emotional Learning (CASEL), which aims to make evidence-based SEL an integral part of state education. CASEL has supported 'meta-analyses' of SEL interventions (CASEL, 2017) and leads efforts to innovate in SEL practices and its measurement (McKown, Read \& Bookman, 2017). Likewise, the National Commission on Social, Emotional, and Academic Development (NCSEAD), coordinated by the Aspen Institute, has produced an 'evidence base'-drawing from psychology, neuroscience, economics and medicine- that SEL should be integrated with academic instruction (Jones \& Kahn, 2017).

At national government scales, similar statements have been made about SEL and its improvement. The US Office of Educational Technology in the Department of Education published a report in 2013 to encourage a shift in educational priorities to promote not only content knowledge, but also grit, tenacity, and perseverance, and proposed the use of technical systems to measure noncognitive factors and student dispositions such as levels of frustration, motivation, confidence, boredom, and fatigue. Notably, in 2015 a new US federal law, the Every Student Succeeds Act (ESSA), made it compulsory for states to provide at least one measure of noncognitive learning - twinned with greater involvement for the ed-tech industry in state schooling - which has made the quantification of growth in non-cognitive skills into a new accountability mechanism schools are obliged to meet (Zernike, 2016).

In the UK, the Department for Education has also actively funded policy research to investigate the application of behavioural economics 'to promote desired behavioural changes amongst young people’ (Bradbury, McGimpsey \& Santori, 2013, p. 251). The Education Endowment Foundation - a government funded source of guidance and research for educators - has produced a SEL toolkit which advances 'interventions which target social and emotional learning' and 'seek to improve attainment by improving social and emotional dimensions of learning, as opposed to focusing directly on the academic or cognitive elements of learning.' A 'Character and Resilience Manifesto' was produced by a cross-party parliamentary committee in 2014, described by Bates (2017) as a 'psycho-economic' fusion of psychological discourse with economic goals around valuable labour market skills. Specific algorithms and metrics have already been devised by prominent psycho- 
economic centres of expertise to measure the economic value of SEL (Belfield et al, 2015).

Psychological entrepreneurs have created a publishing and training micro-industry around SEL. Angela Duckworth, founder of the Character Lab, has written significantly about 'grit' and the measurement of 'personal qualities.' The journalist Paul Tough has published extensively on character and grit in education. Nobel laureate James Heckman has sought to apply behavioural economics to the early development of character in children. Additionally, Carol Dweck has turned her theory of 'growth mindset' into practical techniques that she has successful marketed not only to the education sector but also to Silicon Valley technology entrepreneurs.

Education data science has begun a process of 'datafication' of SEL. According to education data scientists, techniques of measuring the 'emotional state' of learners include collecting proximal indicators that relate to 'non-cognitive factors' in learning, such as academic persistence and perseverance, self-regulation, and engagement or motivation (Pea, 2014). They have developed methods to measure student characteristics such as differences in levels of academic motivation, attitudes toward content, attention and engagement styles, expectancy and incentive styles, persistence through adversity, as well as tenacity or grit (Piety, Hickey \& Bishop, 2014).

As Piety et al (2014) have further noted, education data science is increasingly seen as the community dealing with big data in education, and is consequently attracting funding from governmental, philanthropic and foundation sources. With SEL also attracting funding, government advocacy and inter-governmental support from the OECD and WEF, there are costs for other forms of research that might interrogate the social determinants of complex educational issues. These costs are fiscal and ontological: fiscal in that funding for research and development is being diverted to support SEL; and ontological in that the complex problems of students' behaviours and feelings are understood to be knowable, explainable and intervene-able through computer-mediated psychological lenses and metrics, rather than as the socially situated and contingent effect of complex social, political and commercial processes.

The rest of this article presents examples of how education data science approaches are being mobilized to enact the psycho-policy agenda associated with the SEL movement, focusing on the use of behaviour management apps to track and build 'character'; the development of affective computing techniques to measure emotions from facial expressions; and finally the design of wearable biometric devices that can detect and monitor the emotions through the skin. 


\section{Character tracking}

A key idea emerging from the amalgamation of education data science and psychoinformatics with social-emotional learning is that of using behaviour monitoring apps to develop learners' positive behaviours and 'build character.' The prominent application of these ideas is the successful product ClassDojo. ClassDojo is one app among a fast-growing marketplace of products now aimed at measuring and assessing students' social-emotional learning which (supported by influential organizations such as CASEL) has expanded through direct investment, funding competitions and the publication of 'design principles' for appropriate technologies (McKown et al 2017). These technologies of 'affective capture,' as Nemorin (2017, pp. 11-12) has documented, 'profoundly shape the emotions of students' and are 'a means of positively influencing students' affective capacities.' Widely used by millions of teachers around the world, ClassDojo is perhaps the most globally successful educational technology for affective capture in schools, and a major relay of the priorities of SEL policy ideals into classroom practice.

In practice, ClassDojo allows teachers to award 'positive points' to observed pupil behaviours on a smartphone while working in the classroom. As pupils accumulate these points, the online ClassDojo platform produces simple and accessible data visualizations to show teachers and pupils how many points they have been awarded under a variety of categories. Although the categories are customizable, the developers of ClassDojo have claimed explicitly that the product is informed by the work of several thought leaders in psychology and behaviour changeincluding Heckman's work on 'building character, Duckworth's on 'grit,' and Carol Dweck's work 'growth mindsets and praise' - and seeks to promote 'character strengths' such as curiosity, creativity, teamwork and persistence (Meads, 2013). A key psychological insight in relation to so-called SEL, character and growth mindset is that these qualities are not only measurable but also malleable (Jones \& Kahn, 2017) and therefore the legitimate focus for pedagogic intervention (Bates, 2017). As such, teachers using ClassDojo are compelled to direct their attention to record observable behavioural signals that correlate with psychological categories, and to intervene to mould appropriate behaviours when the data indicates necessary.

Based in Silicon Valley, ClassDojo has actively entered into partnership with Carol Dweck. Her theory of growth mindsets makes the claim that teaching people to focus on 'process' rather than on intelligence or talent, produces high achievers in school and in life:

Parents and teachers can engender a growth mind-set in children by praising them for their persistence or strategies (rather than for their intelligence), by telling success stories that 
emphasize hard work and love of learning, and by teaching them about the brain as a learning machine. (Dweck, 2015)

Dweck's research centre at Stanford University, the Project for Education Research That Scales (PERTS), formed a partnership with ClassDojo in 2016 to produce and disseminate a series of growth mindset animations. Viewed millions of times online at schools around the world, the videos generated significant media attention from the educational, technology and business publication industries alike. The stated ambition of PERTS for involvement in the animations is that 'We want teachers to think about the kind of norms they want to set in the classroom, so growth mindset is integrated in it' (van Dijk, 2016).

As an application for tracking children's character development and strengths, ClassDojo represents a hybridization of SEL theories and explanations drawn from positive psychology and behaviour change science along with 'persuasive computing' design. Persuasive computing is the field dedicated to changing people's behaviours through the design of 'triggers' and 'nudges' (Fogg 2002) and has become central to 'exploiting people's psychological vulnerabilities' through social media (Lewis, 2017). In this sense, ClassDojo has been designed to nudge learners toward new persistent behavioural routines that are consistent with the vision of character development and growth mindset popularized by psychological thought leaders. As a sociotechnical diffuser of the growth mindset theory through persuasive computing techniques, ClassDojo is intended to shape preferred classroom behaviours as prescribed by contemporary psychological experts.

Additionally, ClassDojo normalizes techniques that seek to quantify growth in non-cognitive skills in classrooms, as well as normalizing forms of psychological surveillance which involve tracking and visualizing individuals' behaviours. In these ways, ClassDojo is consistent with the aspirations of global education policy influencers such as the OECD and WEF which have both promoted the idea that social-emotional skills are measurable, malleable and improvable, not least through technological means. It is consistent too with the advocacy of powerful campaigning groups such as CASEL and the NCSEAD, which have collated and disseminated evidence that SEL is an essential substrate to academic progress. As a result, schools are increasingly under pressure to demonstrate effectiveness in promoting SEL — a demand for which ClassDojo is ideally situated as a device for shaping qualities by which schools will be assessed and held accountable. It is, ultimately, a technology of psycho-compulsion and behaviour modification that encourages teachers to award positive value and feedback to behaviours that have been deemed by psychological experts to be appropriate to the development of qualities of character development, grit and growth mindset, and one that enacts psycho-policy priorities around the measurement and moulding of positive affects directly within the pedagogic routines of the classroom. 
This is ontologically problematic, since the app is designed to encourage teachers to observe and record behavioural data related to psychological categories pertaining to the emotional substrates of learning that are themselves deeply contested, particularly when it comes to their measurement and assessment (Duckworth \& Yeager, 2015). Yet by rewarding students for behaviours that are compliant with such categories, teachers using ClassDojo are themselves intervening in moulding such qualities. In this sense, while ClassDojo has been 'authored' through a mixture of Silicon Valley business practice, psychological expertise and technical innovation, it also has an 'authoring' function as it intervenes to shape the attention of teachers to focus on behaviours that indicate the development of growth mindset and character qualities. Its authoring role is then extended to imprinting on students' bodies, as they are nudged and persuaded by the app's reward functionality to behave in ways consistent with normative psychological prescriptions.

\section{Affective computing}

Behaviour tracking apps like ClassDojo seek to nudge learners in the direction of positive behaviours, but more technically advanced developments in 'affective computing' have been imagined as providing ways to actively shape learners' emotions in a more automated fashion. The field of affective computing relies on the development of systems that can collect physiological data from the user, often through facial recognition software and algorithms. The user's emotion can then be classified using some theory of how emotions express themselves physiologically, with training sets of data used to teach an algorithm to identify particular emotions, thus allowing the system to respond appropriately and even simulate human emotions in a way recognizable to humans. In this way, affective computing might potentially influence the human user, increasing persuasiveness, and in some cases deliberately generate a particular emotional response in the user (Rose, Aicardi \& Reinsborough, 2016).

Affective computing has become a significant field of academic research and development, including the establishment of spin-out companies. Affectiva, for example, originated in research at MIT Media Lab, and has built what it claims to be the world's largest emotion database by analysing nearly 5 million faces and compiling 40 billion emotion data points. It uses a range of emotion and facial metrics to measure seven emotions - anger, sadness, disgust, joy, surprise, fear and contempt, as well as valence and engagement—and utilizes precise emotion classifiers that have been trained used deep learning techniques trained on massive amounts of data to enable its 'algorithms to accurately analyze faces "in the wild".' Though its main business is in measuring consumer engagement for the advertising 
and media industries, its applications extend to education, where Affectiva claims 'emotion analytics can be an early indicator of student engagement, driving better learning outcomes.'

Such systems have been endorsed enthusiastically in the World Economic Forum visionary report on fostering social and emotional learning through technology (WEF, 2016). One of its key future ideas is that affective computing innovations will allow systems to recognize, interpret and simulate human emotions, using webcams, eye-tracking, databases of expressions and algorithms to capture, identify and analyse human emotions and reactions to external stimuli, and to differentiate between emotions such as happiness, fear, surprise and confusion. 'This technology holds great promise for developing social and emotional intelligence,' the WEF report claims, specifically citing Affectiva as an exemplar product.

Recently, the Silicon Valley magazine for educational technology, EdSurge, produced a promotional article for the role of 'emotive computing in the classroom.' Emotionally intelligent robots, its author claimed, 'may actually be more useful than humans' in some aspects of teaching, 'as they are not clouded by emotion, instead using intelligent technology to detect hidden responses. ... Emotionally intelligent computing systems can analyse sentiment and respond with appropriate expressions, enabling educators to deliver highly-personalized content that motivates children' (Spreeuwenberg, 2017). The article again endorses emotive systems that appear to have the capacity to take objective readings of learners' emotions and respond in an appropriate register, thus supporting the normative education data science ideal of 'personalized learning' not just by individualizing content but by adapting to individual affective differences.

Similarly, the education data science endeavour to create 'learning analytics' applications has also led to the development of 'emotion learning analytics' platforms. Emotion learning analytics involves the identification and measurement of behavioural indicators from learners through content analysis, natural language processing, big data techniques of sentiment analysis and 'machine emotional intelligence,' and , it is claimed, 'With increased affordances to continuously measure facial and voice expressions with tablets and smartphones, it might become feasible to monitor learners' emotions in real-time' (Rienties \& Rivers, 2014). One function of emotion learning analytics is to perform affect detection from bodily signals, whereby embodied affects are understood to be 'machinereadable' as observable signals. In this model, the automated detection of affect from embodied signals is enabled by video recordings, 'computer vision programs' and 'motion filtering algorithms' which can identify 'facial action units,' head pose and body movement and correlate these observable signals to an underlying emotion classification model using machine learning methods to build detectors of 
each affective state' (D'Mello, 2017, p. 118). As an indication of developments in this direction, the prototype product EngageSense has been used to demonstrate how computer-mounted webcams connected to facial recognition software and computer vision algorithms could be used to measure and monitor levels of emotional engagement through eye-tracking and facial expression.

Behind the glossy promotional discourse and prototypical applications of affective computing for education lies a complex of psychological and physiological theories about how to detect and classify the emotions. Techniques of affective computing include textual sentiment analysis that can be performed through natural language processing, tone analysis and linguistic analysis; speech analysis applications that can detect emotion from common biological signals in the human voice through sonic algorithms; although facial analysis and machine vision algorithms are the main applications. For example, face-reading technologies consist of facial detection, eye tracking, and specific facial position analytics that are based on the development of Facial Action Coding Systems in the 1970s to correlate muscular signals and physiological indexes to their emotion explanation (Rose et al, 2016). Such face-coding systems are designed to read affect from unconscious biological signals, and have been significantly advanced through machine vision R\&D undertaken recently by Facebook's DeepFace project and Google's TensorFlow. For some critics, it is important to be aware that machine vision developments are not merely metric snapshots, but much more actively intervening in people's lives:

machine vision is becoming evermore active. Its continued expansion is starting to have profound effects on human life.... Images have begun to intervene in everyday life, their functions changing from representation and mediation, to activations, operations, and enforcement. Invisible images are actively watching us, poking and prodding, guiding our movements, inflicting pain and inducing pleasure. (Paglen, 2016)

As machine vision systems have become attached to social media platforms, they are being 'trained' on images of people to build increasingly accurate databases and AI systems. These systems can then tell people how they feel based on calculations performed by a dense infrastructure of emotion and facial metrics, webcams and computer vision software, physio-psychological codes and classifiers, machine learning or deep learning techniques, and predictive analytics.

Within education, systems like Affectiva could compile an 'emotional fingerprint' of the individual, which might follow her lifelong, utilizing predictive analytics to anticipate likely emotional engagement with situations and content, and then offering feedback in the shape of prompts or nudges to reshape her behaviour in the direction of more positive engagement. As with nudging and triggering techniques of behaviour change science, the promise of affective computing and machine vision in the classroom is to bypass individual subjective judgment and 
instead enable emotionally intelligent computers to read the unconscious emotional signals that individuals express through their faces and eyes, and utilize these objective data for automated decision-making and hypernudging.

\section{Biometric mood monitoring}

Beyond the use of facial and emotion metrics, the psycho-informatic approach of education data science has been extended to the use of wearable biometric sensing systems. 'Biosensing' refers to practices using technology to understand bodies and the environments in which they live, using either 'wet sensors' that combine a biological element (sweat, saliva, blood) with physiochemical detector, analyse it and convert it into an electrical signal or display, or 'dry sensors' which indicate something about body and its environment by detecting movement in space, heart rate, or even brain activity (Nafus, 2016). Biosensor technologies therefore include accelerometers, altimeters, digital cameras, electrocardiograms (ECG), electromyography (EMG), electroencephalogram (EEG) scanners, electrodermography, location GPS, microphones, oximeters, Bluetooth proximity detectors, pressure gauges and thermometers. Some of these technologies can be embedded in wearable devices including smartwatches, as well as headbands, sociometric badges attached to the skin, and sensors embedded in clothing. Together, these technologies can capture detailed real-time information about heart and brain activity, mental attention, social interaction, and physical and emotional well-being, as well as delivering 'personalized, immediate and goaloriented feedback which could assist with behaviour change interventions' (Piwek et al, 2016).

Education data science practitioners and promoters have not been slow to see the potential of wearable biometric devices to support social-emotional learning. The World Economic Forum (WEF, 2016) has noted that using wearable biosensors to track physical responses to learning situations can 'provide a minute-by-minute record of someone's emotional state,' and thus potentially help to build social and emotional skills. It specifically endorses biometric, electrodermal skin response sensors to measure student engagement, such as 'engagement pedometers' and 'electrodermal activity sensors' that send a small current across the skin and measure changes in electrical charges as the sympathetic nervous system responds to stimuli. Such devices treat skin conductance as a physiological indicator of an emotionally aroused response, and are based on biomedical models of the physiological signals that indicate physical, emotional or cognitive arousal. The WEF report highlights wearable products produced by the commercial company Empatica which can measure emotionally aroused responses such as stress and anxiety, and then vibrate to nudge its user 'to switch to a more positive response.' 
Notably, Empatica is a spin-out of the same MIT Media Lab program that established Affectiva, also promoted by the WEF.

Like other wearable devices, Empatica relies on psychological classification systems to measure mood. Most products for measuring the emotions depend on background science such as the Positive and Negative Affect Scale (PANAS) or the Geneva Emotion Wheel to link information from the user to existing psychological classifications and standards of emotional measurement. PANAS, for example, originated as a self-completion survey which allowed psychologists to identify and classify signals of either negative affect (scared, nervous, irritable, hostile, guilty, ashamed, upset etc.) or positive affect (active, attentive, determined, excited, inspired, interested and so on). Wearable emotion sensors enact these classification systems, using algorithms that have been trained to predict the likelihood that a physiological signal is associated with a particular emotional classification to then produce data about the user's emotions in the form of a display or visualization. These data can then be used to produce feedback on how to improve in the direction of positive affect based on a real-time assessment.

Such techniques are likely to extend in the scope of their capacity to read the emotions from the body. The recent summary of 'emotive computing in the classroom' produced by EdSurge has identified a number of relevant ongoing technical innovations:

- Transdermal Optical Imaging, with a camera that is able to measure facial blood flow information and determine student emotions where visual face cues are not obvious

- Electroencephalogram (EEG) electrical brain activity tests to measure students' emotional arousal, task performance and provide computer mediation to individuals

- Wearable social-emotional intelligence prosthetic which uses a small camera and analyzes facial expressions and head movements to detect affects in children in real-time

- A glove-like device that maps students' physiological arousal an measures the wearer's skin conductivity to deduce excitement, engagement or fatigue and stress (Spreeuwenberg, 2017)

Techniques such as Transdermal Optical Imaging propose to penetrate beyond the skin, going beyond the affective computing techniques of machine vision and facial and emotion metrics to detect mood in the blood. Wearable EEG headbands seek to go further by detecting the emotions within the activity of the brain itself, rather than through the signals produced through the sympathetic activation of the skin.

In a recent study of wearable real-time mood-monitoring, Davies (2017) argues that these technologies of 'affective capture' represent new ways of 'valuing' the emotions, where the emotions become the object of assessment and judgment, and from there the targeted object of modification. Real-time mood-tracking devices, he argues, are intended to achieve a form of 'emotional augmentation,' to 
transform it and 'render that emotion preferable in some way (be it more positive, more acceptable, simpler etc.),' and therefore 'turning it into a different emotion,' especially those emotions deemed more valuable in terms of their economic benefits (Davies, 2017, p. 43).

As the enthusiasm of organizations such as the WEF and OECD for improving learners' social-emotional learning demonstrate, the emotions are now being valued in terms of potential economic maximization. Learners' emotional wellness has been associated with creativity, innovation and productivity, turning their emotions into a form of capital in much the same way that test scores have been treated as proxy indicators of 'human capital,' national progress and comparative advantage by international standardized tests such as the OECD's Programme for International Student Assessment (PISA). These psycho-economic organizations are seeking to change learners' emotions in the direction of positive affect, and promote wearable emotion technologies as a way of measuring, assessing and judging learners' existing emotions, then imposing psychological interventions to transform 'deficit' emotional arousal into socially, economically and politically preferred forms of emotional arousal.

\section{Psycho-informatic power}

Psycho-informatics in education includes devices such as ClassDojo that can be used to record observable behavioural signals that correlate with the emotional substrates of learning; facial vision algorithms that read faces for physiological signals of underlying emotional responses; and wearable biometrics that detect electrical signals from the body as a measure of nervous system arousal. These psycho-informatic techniques, then, are seeking to burrow into the body of the student, going beyond measurement of observable behaviours to unconscious muscular movement in the face and biological processes beneath the skin.

Computational psychology proceeds from an ontology of psychometric realism that assumes the complexities of human emotion and behaviour can be scraped from the body by computational means, read and understood via metric methods, and then mediated or modified through emotional feedback and psychocompulsion techniques. As current examples like 'weaponized' psychological propaganda and automated behaviour change show, the combination of big data analytics with computational psychology is being treated seriously (both by its proponents and its critics) as a viable way for individuals and whole populations to be emotionally manipulated and behaviourally modified for particular political purposes (Lewis, 2017). Beer (2017) has suggested that claims big data can 'enable an understanding of our "deepest" emotions, rendering them targetable,' is typical 
of the data analytics industry and market, which 'seeks to attach powerful promises to data analytics.'

Indeed, the ontological promise of data analytics that human behaviour and affects are knowable and nudge-able by computational means also makes them financially attractive-not just for profit-seeking investors, but for philanthropic funders seeking to leverage influence and for government departments and policymakers seeking effective, efficient and value-for-money solutions to intractable social problems. Computational psychology and its political corollary psycho-policy direct a kind of correctional gaze on to the psychological correlates of human emotions and embodied behaviours, promising value-for-money fixes for psychological fragility and the activation of preferable positive emotions, rather than interrogating and challenging the more complex social, political and commercial influences that co-determine individual and collective affect. Moulding student emotions has become a seemingly smart investment: it reduces behaviour problems in classrooms and reduces the 'costs' of student non-compliance, and longer-term produces workplace-ready individuals who are equipped to perform 'emotional labour' (Bates, 2017). SEL has also been identified by organizations such as CASEL and NCSEAD as the substrate to academic learning, and as such is mutating into accountability mechanisms by which schools may be measured and ranked.

Through its employment of computational psychology and psycho-informatic technologies, education data science is positioning itself as a new institution of power in education, comprising an interlocking complex of psy-sciences, commercial companies, government agendas, and policy influencers, as well as hardware, software, databases, analytics and algorithms. It is seeking to enact social-emotional learning psycho-policies by measuring behaviours and emotions, then imposing hypernudges and interventions to improve positive affectultimately teaching lessons in how an emotionally positive life ought to be lived, as defined by the experts of positive psychology. These forms of psycho-compulsion to embody preferred forms of social and emotional conduct are the product of a combination of the 'lines of code' written in the languages of computing with the preferred 'codes of conduct' defined by psy.

The aspiration to enhance SEL is also significant because it is animated by a desire to instantiate a shift in power over education as a whole. Anagnostopoulos, Rutledge and Jacobsen (2013) have noted that educational power has been concentrated in recent years in the hands of organizations that have control of the 'infrastructure of test-based accountability.' For decades, education systems, schools, teachers and learners alike have been the subjects of national and international testing, and the comparisons and judgments which follow from the 
ways that test data are compiled into performance measures, ratings and rankings by government agencies and non-governmental international organizations. As such, they define a form of 'informatic power' which

depends on the knowledge, use, production of, and control over measurement and computing technologies ... to produce performance measures that appear as transparent and accurate representations of the complex processes of teaching, learning, and schooling. As they define who counts as 'good' teachers, students, and schools, these performance metrics shape how we practice, value and think about education.

(Anagnostopoulos et al, 2013, p. 11)

With the turn to computational psychology by education data science, a new form of 'psycho-informatic power' is emerging in education. Focused on 'affective capture' through digital apps and platforms rather than test scores, measures and rankings, psycho-informatic power emphasizes a psycho-realist ontology that social-emotional metrics and technologies can be used to define what and who counts as a 'good' student, teacher or school. Measures of grit, growth mindset and emotional arousal that can be captured via behaviour tracking, affective computing and biometrics matter most for those political, academic, philanthropic and commercial actors that seek to gain from their possession of psycho-informatic power. Emotion metrics are the new sources of power in psycho-informatic approaches to the measurement of students, teachers and schools.

Moreover, financial forms of psychological capital are available for accumulation by those researchers who seek to gain from academic funding for their interventions into SEL, as well as from the uptake and impact of their theories and the techniques they have developed to test and evidence them. Psycho-political capital is available to those policy makers able to drive forward the use of new psychological theories and techniques, who might then use it as a competitive advantage to 'lend' their approaches to other sites through new circuits of national and international psycho-policy borrowing. Global actors such as the OECD and WEF, as well as national-based organizations such as CASEL and NCSEAD, are seeking psychological capital too, by positioning themselves as global expert centres for the dissemination of practices, assessment instruments and technologies related to SEL, while commercial organisations stand to gain from venture capital investment and spending on their products. In these ways, psychoinformatic power is being concentrated among actors that crisscross academic, governmental, philanthropic and commercial sectors. Arguably, too, schools will be able to leverage forms of psychological capital as social-emotional measurement and the shaping of students' positive feelings become techniques of school accountability, evaluation and ranking.

Perhaps most critically, psycho-informatic power may even challenge democracy, as the psychological tricks of social media potentially mould people's attention, 
sentiments and desires to be attuned to dominant political and commercial priorities, and erode capacities of reason and decision-making central to selfgovernance (Lewis, 2017). The techniques of persuasion and nudging coded in to technologies of computational psychology may be priming people 'to dwell in a purely "real-time" cognitive state (feeling, experiencing, responding and liking) and allowing machines to perform acts of judgment, evaluation and decision-making' (Davies, 2017, pp.38-39) on their behalf. Recontextualized in schools, these psychological techniques raise significant issues regarding capacities of judgment, discrimination and decision-making that are so central to the development of young people as informed participants in democracy.

\section{Conclusion}

This article has provided a mapping of new forms of computational psychology emerging in education, outlined the policy context in which it is situated, and traced the ontology underpinning it and the forms of psycho-informatic power, finance and algorithmic governance it produces. Both ontologically and financially underpinned by specific software-powered techniques and practices of algorithmic governance, as well as by psycho-policy techniques of nudging, psycho-informatic power describes how schools, teachers and national governments are being compelled to drive up standards of social-emotional learning, and how powerful actors are exerting control over the knowledge and technologies required to measure, report, and target progress in the direction of preferred forms of positive affect. The organizations supporting computational psychology in education possess practical know-how to improve behaviours and emotions, creating technologies to both capture and nudge learners to exhibit the non-cognitive qualities against which schools themselves may be measured and held accountable.

As has been shown, psycho-informatic technologies are being authored in a variety of sites, from the ed-tech studios of Silicon Valley startups such as ClassDojo, to academic education data science labs, to the MIT spin-out companies of Affectiva and Empatica. Mining and moulding student emotions has become profitable for these organizations. Support for their apps and platforms is emanating from global policy influencers, psychological entrepreneurs, and campaigning coalitions, all of it situated in a specific psycho-policy context in which the social-emotional aspects of learning and concepts such as character and growth mindset are enjoying political advocacy. However, psycho-informatic educational technologies are not just being authored and disseminated. They are also authoring devices which are being used to imprint particular forms of positive affect on to students, for various purposes of controlling classroom behaviours, moulding productive emotional labour, and measuring school effectiveness. The informatic power of test-based 
data and technologies which has impacted on students and teachers in recent years is mutating into a form of real-time psycho-informatic power that utilizes algorithmic techniques along with psychological classifications and methods to nudge and modulate learners' affects and pre-emptively shape their possible behaviours.

\section{References}

Albright, J. (2016). How Trump's campaign used the new data-industrial complex to win the election. LSE US Centre blog, 26 November 2016:

http://blogs.lse.ac.uk/usappblog/2016/11/26/how-trumps-campaign-used-the-new-dataindustrial-complex-to-win-the-election/

Anagnostopoulos, D., Rutledge, S. A. \& Jacobsen, R. (2013). Mapping the information infrastructure of accountability. In: Anagnostopoulos, D., Rutledge, S. A. and Jacobsen, R. (eds), The Infrastructure of Accountability: data use and the transformation of American education. Cambridge, MA: Harvard Education Press, pp. 1-20.

Anderson, B. \& Horvath, B. (2017). The Rise of the Weaponized AI Propaganda Machine. Medium, 12 February: https://medium.com/join-scout/the-rise-of-the-weaponized-aipropaganda-machine-86dac61668b

Bates, A. (2017). The management of 'emotional labour' in the corporate re-imagining of primary education in England. International Studies in Sociology of Education 26, no. 1: 66-81.

Belfield, C., Bowden, B., Klapp, A., Levin, H., Shand, R. \& Zander, S. (2015). The economic value of social and emotional learning. Center for Benefit-Cost Studies in Education, Teachers College, Columbia University.

Beer, D. (2017). Visions of an all-seeing, all-knowing politics. Medium, 28 February: https://medium.com/@,davidgbeer/visions-of-an-all-seeing-all-knowing-politics-c7b45ff23239

Bradbury, A., McGimpsey, I. \& Santori, D. (2013). Revising rationality: the use of 'nudge' approaches in neoliberal education policy. Journal of Education Policy, 28 (2): 247-67.

Cadwalladr, C. (2017). The great British Brexit robbery: how our democracy was hijacked. The Guardian, 7 May 2017: https://www.theguardian.com/technology/2017/may/07/the-greatbritish-brexit-robbery-hijacked-democracy

CASEL. 2017. (2017). Meta-Analysis: A Major New Research Study. CASEL, 12 July: http://www.casel.org/2017-meta-analysis/

D’Mello, S. (2017). Emotional learning analytics. In Lang, C., Siemens, G., Wise, A. \& Gasevic, D. (eds) Handbook of Learning Analytics, 1st edn: 115-127. Society of Learning Analytics Research.

Davies, W. (2017). How are we now? Real-time mood-monitoring as valuation. Journal of Cultural Economy 10 (1), pp. 34-48

Duckworth, A.L. and Yeager, D.S. (2015). Measurement matters: assessing personal qualities other than cognitive ability for educational purposes. Educational Researcher, 44 (4), pp. 237-51. 
Dweck, C. S. (2015). The secret to raising smart kids. Scientific American, 1 January: www.scientificamerican.com/article/the-secret-to-raising-smart-kids1/

Fogg, B. J. (2002). Persuasive technology: using computers to change what we think and do. Ubiquity, December, pp. 89-120.

Foucault, M. (2008). The Birth of Biopolitics: Lectures at the Collège de France, 1978-1979. Edited by M. Senellart, trans. G. Burchell. New York: Palgrave Macmillan.

Friedli, L. and Stearn, R. (2015). Positive affect as coercive strategy: conditionality, activation and the role of psychology in UK government workfare programmes. Medical Humanities 41, pp. 4047.

Gillespie, T., Boczkowski, P.J. \& Hood, S. (2014). Media Technologies: Essays on communication, materiality, and society. London: MIT Press.

Grasseger, H. \& Krogerus, M. (2017). The data that turned the world upside down. Motherboard, 28 January: https://motherboard.vice.com/en us/article/how-our-likes-helped-trump-win

Jasanoff, S. (2015). Future imperfect: science, technology, and the imaginations of modernity. In Jasanoff, S. and Kim, S-H. (eds), Dreamscapes of Modernity: sociotechnical imaginaries and the fabrication of power. Chicago, IL: University of Chicago Press, pp. 1-33.

Jones, S.M. \& Kahn, J. (2017). The Evidence Base for How We Learn: Supporting Students' Social, Emotional, and Academic Development. The Aspen Institute, 13 September: https://assets.aspeninstitute.org/content/uploads/2017/09/SEAD-Research-Brief9.12 updated-web.pdf

Jones, R., Pykett, J. and Whitehead, M. (2013). Changing Behaviours: on the rise of the psychological state. Cheltenham: Edward Elgar.

Kitchin, R. \& Dodge, M. (2011). Code/Space: Software and everyday life. London: MIT Press.

Lemke, T. (2011). Biopolitics: An advanced introduction. London: New York University Press.

Lewis, P. (2017). 'Our minds can be hijacked': the tech insiders who fear a smartphone dystopia. The Guardian, 6 October:

https://www.theguardian.com/technology/2017/oct/05/smartphone-addiction-silicon-valleydystopia

Lynch, T.L. (2015). The Hidden Role of Software in Education: From policy to practice. London: Routledge.

Lynch, T.L. \& Gerber, H.R. (2017). The ontological imperative when researching the digital. REF

Markowetz, A., Błaszkiewicz, K., Montag, C., Switala C. and Schlaepfer, T. E. (2014). Psychoinformatics: big data shaping modern psychometrics. Medical Hypotheses 82 (4), pp. 405-411.

McGimpsey, I., Bradbury, A. and Santori, D. (2016). Revisions to rationality: the translation of 'new knowledges' into policy under the coalition government. British Journal of Sociology of Education: $\underline{\text { http://dx.doi.org/10.1080/01425692.2016.1202747 }}$

McKown, C., Read, L. \& Bookman, N. (2017). Key Design Principles for Direct Assessments of SEL: Lessons Learned from the First Design Challenge. CASEL, September: 
http://measuringsel.casel.org/wp-content/uploads/2017/09/AWG-Design-Challenge-DirectAssessments-of-SEL.pdf

Mead, S. (2013). Profile of ClassDojo Founders Sam Chaudhury and Liam Don. Education Week, 11 June:

http://blogs.edweek.org/edweek/sarameads policy notebook/2013/06/sam chaudhary and liam don co-founders classdojo.html

Moore, M. (2016). Tech giants and civic power. London: Centre for the Study of Media, Communication and Power, King's College.

Nafus, D. (2016). Introduction. In Nafus, D. (ed.), Quantified: biosensing technologies in everyday life. London: MIT Press, pp. ix-xxxi.

Nemorin, S. (2017). Affective capture in digital school spaces and the modulation of student subjectivities. Emotion, Society and Space 24, pp. 11-18.

OECD-CERI. (2015). Skills for Social Progress: The Power of Social and Emotional Skills. OECD Skills Studies, OECD Publishing.

Paglen, T. (2016). Invisible images (your pictures are looking at you). The New Inquiry, 8

December: http://thenewinquiry.com/essays/invisible-images-your-pictures-are-looking-atyou/

Pea, R. (2014). A Report on Building the Field of Learning Analytics for Personalized Learning at Scale. Stanford: Stanford University.

Piety, P. J., Hickey, D. T. and Bishop, M. J. (2014). Educational data sciences - framing emergent practices for analytics of learning, organizations and systems. $L A K$ '14, 24-28 March, Indianapolis.

Peters, M. \& Tesar, M. (2017). Bad research, bad education: The contested evidence for evidence-based research, policy and practice in education. In J. Lynch, J. Rowlands, T. Gale, A. Skourdoumbis (eds). Practice theory: Diffractive readings in professional practice and education. Abingdon: Routledge, pp.231-246

Pitts-Taylor, V. (2016). The Brain's Body: Neuroscience and corporeal politics. London: Duke University Press.

Piwek, L., Ellis, D.A., Andrews, S. \& Joinson, A. (2016). The Rise of Consumer Health Wearables: Promises and Barriers. PLoS Med 13(2): e1001953. doi:10.1371/journal.pmed.1001953

Rabinow, P. \& Rose, N. (2006). Biopower today. BioSocieties 1, pp. 195-217.

Rienties, B. and Rivers, B. A. (2014). Measuring and Understanding Learner Emotions: evidence and prospects. Bolton: University of Bolton.

Rose, N. (1999). Governing the Soul: the shaping of the private self (2nd edn). London: Free Association Books.

Rose, N., Aicardi, C. \& Reinsborough, M. (2016). Future Computing and Robotics: a Foresight report from the Human Brain Project lab. London: King's College London. 
Rouvroy, A. \& Berns, T. (2013). Algorithmic governmentality and prospects of emancipation: Disparateness as a precondition for individuation through relationships? Reseaux 177, pp. 163196.

Ruppert, E., Isin, E. \& Bigo, D. (2017). Data politics. Big Data \& Society, July-December: 1-7.

Spreeuwenberg, R. (2017). Does emotive computing belong in the classroom? EdSurge, 4 January: https:// www.edsurge.com/news/2017-01-04-does-emotive-computing-belong-in-theclassroom

van Dijk, P.E.E. (2016). ClassDojo and PERTS launch growth mindset toolkit. The Stanford Daily, 17 February 2016: http://www.stanforddaily.com/2016/02/17/classdojo-and-perts-launchgrowth-mindset-toolkit/

WEF (World Economic Forum). (2016). New Vision for Education: fostering social and emotional learning through technology. Cologny/Geneva: World Economic Forum.

Williamson, B. (2017). Big Data in Education: The digital future of learning, policy and practice. London: Sage.

Woolley, S.C. \& Howard, P.N. (2017). Computational propaganda worldwide: Executive summary. Working Paper 2017.11. Oxford: Project on Computational Propaganda.

Yeung, K. (2017). Hypernudge: Big Data as a mode of regulation by design. Information, Communication \& Society 20 (1), pp. 118-136.

Zernike, K. (2016). 'Testing for joy and grit? Schools' nationwide push to measure students' emotional skills. New York. Times, 29 February: www.nytimes.com/2016/03/01/us/testing-forjoy-and-grit-schools-nationwide-push-to-measure-students-emotional-skills.html 